
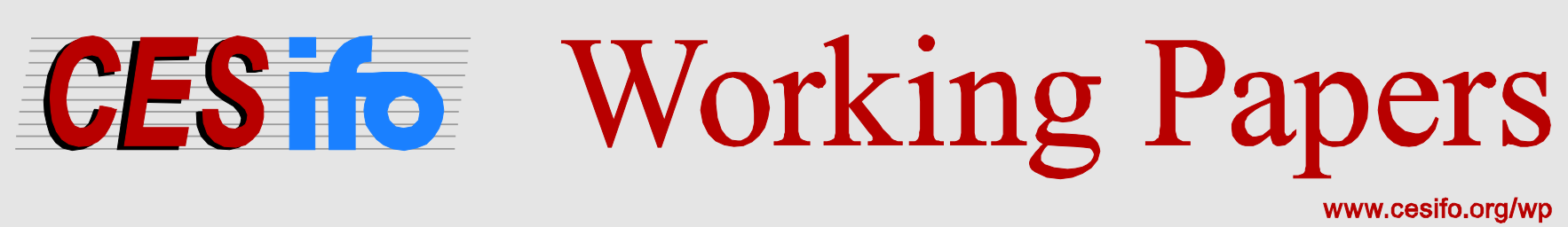

\title{
Monetary Emissions Trading Mechanisms
}

\author{
Cyril Monnet \\ Ted Temzelides
}

\author{
CESIFO WORKING PAPER NO. 4633 \\ CATEGORY 10: ENERGY AND CLIMATE ECONOMICS \\ FEBRUARY 2014
}
An electronic version of the paper may be downloaded
- from the SSRN website:
- from the RePEc website:
- from the CESifo website:
www.SSRN.com
www.RePEc.org
www.CESifo-group.org/wp

\section{CESifo}




\title{
Monetary Emissions Trading Mechanisms
}

\begin{abstract}
Emissions trading mechanisms have been proposed, and in some cases implemented, as a tool to reduce pollution. We explore the similarities between emission-trading mechanisms and monetary mechanisms. Both attempt to implement desirable allocations under various frictions, including risk and private information. In addition, implementation relies on the issue and trading of objects whose value is at least partially determined by expectations, namely money and permits, respectively. We use insights from dynamic mechanism design in monetary economics to derive properties of dynamic emissions trading mechanisms. At the optimum, the price of permits must increase over time. Efficient tax policies are statecontingent, and there is an equivalence between state-contingent taxes and emissions trading. Restrictions resulting from the money-like feature of permits can break this equivalence when there is endogenous progress in clean technologies. These restrictions must be taken into consideration in actual policy implementation.
\end{abstract}

JEL-Code: A100.

\author{
Cyril Monnet \\ University of Bern \\ Study Center Gerzensee \\ Bern / Switzerland \\ cyril.monnet@vwi.unibe.ch
}

\author{
Ted Temzelides* \\ Department of Economics-MS 22 \\ Rice University \\ P.O. Box 1892 \\ USA - 77251-1892 Houston TX \\ tedt@rice.edu
}

*corresponding author

$17^{\text {th }}$ September 2013

First version: September 2010. We thank Peter Hartley and participants at the Environmental Economics and Law Conference at the University of Bern, the CESifo Area Conference on Energy and Climate Economics 2011, and Rice University for comments. 


\section{Introduction}

Under an emissions trading system (also known as cap-and-trade), producers must acquire permits equal to the amount of their emissions in a given period. These permits are then remitted to the issuing institution. ${ }^{1}$ So far, the results from actual implementations of emissions trading have been mixed, and some policy-makers have argued that taxes would be more effective in reducing emissions. Similar criticisms have also appeared in related academic investigations. In a highly publicized recent study, Clï¿œ and Vendramin (2012) criticized certain features of the ETS that have led to low prices for permits. They point out shortcomings, specifically in regard to the ability of emissions trading to induce investment in new technologies. They instead advocate a tax as a more effective non-distortionary instrument leading to price stability and increased clean investments.

Our work takes a different path from the existing literature. It is motivated by the observation that emission-trading mechanisms resemble monetary mechanisms in at least two ways. First, both attempt to implement desirable allocations under various frictions, including risk and private information. Second, in both cases implementation relies on the issue and trading of objects whose value is at least partially determined by expectations, namely (fiat) money and permits, respectively. ${ }^{2}$ Our model is built around the assumption that individual firms have some private information about their need to engage in high emission-intensity activities. As firms are heterogenous regarding their emission-intensity needs, they must be provided with the appropriate incentives in order to efficiently adjust their production levels. We use insights from dynamic mechanism design in monetary economics to derive properties of optimal dynamic emissions trading mechanisms. ${ }^{3}$ We find that a state-contingent tax system can do at least as well as a cap-and-trade system in most cases, and it can dominate it when there is endogenous clean technology adoption. More generally, we argue that policy-makers should think about permit-issue in a manner similar to that used by central bankers. We discuss the determination of the optimal permit-issue policy and find that, at the optimum, the price of permits must increase over time. In the absence of aggregate risk, there is no role for "banking;" i.e., the optimum can be supported even if the permits expire at the end of the specified period of time. When firms can choose the level of technological progress in clean technologies, emissions trading might not be able to implement the efficient allocation. This is because, if there is a high fraction of "dirty firms" in the economy, emissions trading either makes technology adoption by these firms too slow, or it must distort production levels relative to the first best. Interestingly, we demonstrate that fiscal policies do not suffer from this drawback. ${ }^{4}$

In an influential paper, Weitzman (1974) studied price versus quantity-targeting policies in the presence of uncertainty and concluded that their effectiveness depends on the relative elasticities of

\footnotetext{
${ }^{1}$ One of the first such systems was established in the US in 1990 trough the Clean Air Act in order to reduce sulfur dioxide emissions. As a follow-up to the Kyoto protocol, EU countries adopted the so called EU Emission Trading System (ETS) in 2005 in connection to a reduction in carbon emissions.

${ }^{2}$ Of course, a "central permit issuer," an authority similar to a central bank, is not yet in existence. One implication of our analysis is to point out the need for such an authority to be established.

${ }^{3}$ For related applications of dynamic mechanism design to optimal taxation and to monetary theory see, for example, Golosov, Kocherlakota, and Tsyvinski (2003) and Wallace (2012).

${ }^{4}$ Laffont and Tirole (1996) derive a similar result where markets fail to deliver the efficient outcome in a twoperiod model where pollution innovation is endogenous.
} 
supply and demand. However, Weitzman did not consider state-contingent policies. In our model, state-contingent taxes are an important tool towards implementing efficient levels of output and emissions. Requate (2005) surveys the large existing literature on instrument choice and innovation in abatement technologies. The similarity between emissions permits and money is mentioned in Lackner, Wilson, and Ziock (2001). However, to the best of our knowledge, ours is the first paper that explores the implications of formalizing this insight. Blyth, Bradley, Bunn, Clarke, Wilson, and Yang (2007) investigate how environmental policy uncertainty affects investment in low-emission technologies in the power-generation sector. In their model, firms can choose from different irreversible investments. They find that price uncertainty decreases clean investments. Li and Shi (2010) use a static general equilibrium model to compare regulatory emission standards and emission taxes as alternative tools for controlling emissions in a monopolistically competitive industry with heterogenous firms. They find that an emissions standard results in higher welfare than taxes if and only if productivity dispersion among firms is small and dirty firms enjoy a high degree of monopoly power. Brunner, Flachsland, and Marschinski (2011) discuss dynamic aspects of emissions trading, including issues related to credibility. Chen and Tseng (2011) find that investment can be used to hedge against price risk, and it increases with uncertainty. In all these models the price of permits is treated as exogenous. Colla, Germain, and Van Steenberghe (2012) endogenize the price of the permits and study optimal policy in the presence of speculators. The connection between environmental policy and business cycles is discussed in Heutel (2012). Finally, in a recent working paper, Albrizio and Silva (2012) introduce uncertainty over the exogenous policy rule, as well as the possibility of reversible and irreversible investments by firms.

The paper is organized as follows. Section 2 describes the baseline model, while Section 3 studies taxation and emissions trading in a model with technological change. A brief conclusion follows. Technical material and an extension to include a futures market can be found in the Appendix.

\section{The Model}

Time is denoted by $t=0,1,2, \ldots$. The economy is populated by a $[0,1]$-continuum of firms and a $[0,1]$-continuum of workers. Firms and workers discount the future at a rate $\beta \in(0,1)$. There are two goods: labor and a (numeraire) consumption good. Each firm produces the numeraire good using labor. Workers supply labor to the firms and consume the numeraire good. Using $q$ units of labor, each firm can produce $f(q)$ units of the numeraire good. We assume that $f$ is a smooth, strictly increasing, and strictly concave function. Production is costly for the society, as each operating firm creates harmful emissions. When the level of overall emissions is $E$, the utility of workers from consuming $c$ units of the numeraire good and working $q$ hours is $U(c, q, E)=u(c)-q-E .^{5}$ For simplicity, we assume that there is no storage across periods.

We think of the emission-intensity of a firm's operations as being subject to random shocks. For example, these shocks may represent the need to use energy for transportation, or for cooling or

\footnotetext{
${ }^{5}$ Assuming that the negative externality is generated by the flow of emissions makes our analysis readily applicable in the context of conventional pollutants such as $\mathrm{SO}_{\mathrm{x}}, \mathrm{NO}_{\mathrm{x}}$, Mercury, or particulates. As is well known, the stock of accumulated emissions is the relevant variable when one considers externalities related to $\mathrm{CO}_{2}$.
} 
heating due to weather conditions, which are inherently random. More precisely, we assume that in each period, each firm receives a shock, $\theta$, which determines the degree of emissions generated by its production activity. At time $t$, the amount of emissions generated by a firm that received shock $\theta$ and that uses $q$ units of labor is given by $\theta f(q)$. For simplicity, we assume that the $\theta$ 's are iid across time and across firms. We denote the cumulative distribution of $\theta$ by $G(\theta)$, and we assume that its support is the interval $[0, \bar{\theta}] .{ }^{6}$ In order to capture the fact that firms have more information than the regulating authority about their need to use high emission-intensity, we assume that these shocks are private information. This is a relevant and novel feature of our analysis, as it implies that efficient policies need to "elicit information" about the realization of these shocks.

Throughout the paper, we study conditions under which the full-information first-best allocation, hence forth called the "efficient allocation," is supportable. Thus, we will follow the following steps. First, we will characterize the full-information first-best arrangement under certain assumptions on the underlying economic environment. Then we investigate under what conditions various policies, such as taxation or trading in permits, can support the first-best. Of course, in order to be consistent with the private information friction, the policies themselves are not permitted to depend on the true value of the $\theta$ 's. ${ }^{7}$

While all producing firms create pollution, they can also reduce their emissions at some cost. More precisely, given $\theta$, we assume that each firm can reduce its effective emissions to an amount $y$ by incurring the cost $h(\theta q-y)$, where $h(\cdot)$ is the same convex function for all firms, with $h(0)=0$ and $h^{\prime}(0)=0$. We first study the economy in the absence of any policy. In this case, firms maximize their profits without being concerned about their emissions. Since firms only differ in their degree of emissions, in this case they behave homogeneously and maximize their periodby-period profits. Thus, firms in each period $t$ hire $q$ units of labor at market wage $w$ in order to solve

$$
\pi=\max _{q} f(q)-w q
$$

The optimal production satisfies

$$
f^{\prime}(q)=w
$$

and overall emissions, $E$, are given by $E=q \int \theta d G(\theta)$. Taking $E$ as given, consumers maximize their utility subject to their budget constraint. Since the numeraire good is not storable and consumers are homogeneous, there is no scope for savings. Consumers solve:

$$
\begin{array}{ll}
\max _{c, q} & u(c)-q-E \\
& \text { s.t. } c \leq w q+\pi
\end{array}
$$

where $\pi$ is the firm's profit and $E$ is the level of total emissions. The first order conditions imply

$$
w u^{\prime}(c)=1
$$

\footnotetext{
${ }^{6}$ We make these simplifying assumptions for tractability. Assuming that emissions are proportional to the amount of input employed by the firm simplifies the algebra, but the results would not change if emissions were assumed to be proportional to output. Introducing correlated shocks could allow us to investigate business cycle considerations as in Heutel (2012). However, as is well known, dynamic models with private information and serially correlated shocks are not analytically tractable. This is an important avenue for future research.

${ }^{7}$ When there is no aggregate risk, policies can depend on the aggregate $\theta$.
} 
Finally, market clearing gives

$$
c=f(q)
$$

Combining (2) with (4) and (5) we obtain

$$
f^{\prime}(q) u^{\prime}(f(q))=1
$$

We denote by $\bar{q}$ the scale of operation that solves (6). Welfare, $W$, in this economy is then given by

$$
(1-\beta) W=u(f(\bar{q}))-\bar{q}\left(1+\int \theta d G(\theta)\right)
$$

Contrary to private firms, a social planner must take emissions into account when solving for the efficient outcome. It is easy to see that, since firms vary in their degree of emissions, the firstbest would induce different production levels across different firms. The social planner solves the following problem.

$$
\begin{aligned}
& \max _{q(\theta), 0 \leq y(\theta) \leq \theta q(\theta)} u(c)-\int q(\theta)+y(\theta) d G(\theta) \\
& \text { s.t. } \quad c=\int f(q(\theta))-h(\theta q-y(\theta)) d G(\theta)
\end{aligned}
$$

We denote the efficient production scale by $q^{*}(\theta)$ and the efficient level of emissions by $y^{*}(\theta)$. The schedule $\left(q^{*}, y^{*}\right)$ satisfies the following first order conditions for all $\theta$ :

$$
\begin{array}{r}
{\left[f^{\prime}\left(q^{*}(\theta)\right)-\theta h^{\prime}\left(\theta q^{*}(\theta)-y^{*}(\theta)\right)\right] u^{\prime}\left(c^{*}\right)+\theta \lambda_{\theta}=1} \\
h^{\prime}\left(\theta q^{*}(\theta)-y^{*}(\theta)\right) u^{\prime}\left(c^{*}\right)-\lambda_{\theta}+\lambda_{0}=1
\end{array}
$$

where $\lambda_{\theta}$ is the Lagrange multiplier on $y \leq \theta q(\theta)$, and $\lambda_{0}$ is the multiplier on $y \geq 0$. In that case, consumption $c^{*}$ is given by (8).

Clearly, as $h^{\prime}(0)=0$, it is efficient for all firms to reduce emissions by a small amount and all active firms must reduce their emissions at the optimum. Our assumptions also imply that, below a threshold factor, efficiency requires that firms reduce their emissions to zero; i.e., there exists a $\tilde{\theta}>0$ such that $y(\theta)=0$, for all $\theta<\tilde{\theta}$. Above this threshold the optimal ex-post emissions are positive and proportional to the ex-ante emissions. The reason is simple. Our specification implies that the marginal benefit from reducing emissions is the same regardless of whether the reduction comes from a high-pollution or a low-polluting firm. On the other hand, the cost of emissions reduction (in terms of consumption loss) is small if firms are already relatively clean. This is true even if a firm eliminates its emissions entirely, as $h^{\prime}\left(\theta q^{*}(\theta)\right)$ converges to zero when $\theta$ is small. The optimal total emissions level is given by $E^{*}=\int y^{*}(\theta) d G(\theta)$. Interestingly, the efficient allocation dictates that some firms reduce their emissions, by both reducing their production scale and by cleaning their act. Of course, in the absence of taxes or other emission control policies, all firms operate at the same scale and none becomes cleaner.

For later reference, it is instructive to consider the following thought experiment. Consider two economies which are identical except that one is subject to a $\theta$-distribution $G_{0}$, while the other is 
subject to distribution $G_{1}$, where $\int \theta d G_{1}(\theta)<\int \theta d G_{0}(\theta)$. In words, firms are on average cleaner in the economy under $G_{1}$. The efficient allocations in the two economies are such that $\tilde{\theta}_{1}>\tilde{\theta}_{0}$ and, for all $\theta>\tilde{\theta}_{1}$, we have $q_{1}^{*}(\theta)<q_{0}^{*}(\theta)$ and $y_{1}^{*}(\theta)<y_{0}^{*}(\theta)$.

Typically, efficiency will require a reduction in emissions from their laissez-faire levels. One possible tool towards accomplishing this involves a tax. Another possibility involves imposing controls over emissions, together with operating a market for emissions permits, so that firms which pollute most internalize the cost. We first consider an economy where firms participate in a market for permits.

This market operates as follows. If a firm produces $q$, and if its emission shock is $\theta$, it will need to accumulate $\theta q$ emission permits. Alternatively, a firm might invest in order to reduce its pollution to ex-post emission level $y(\theta) \leq \theta q$ and then accumulate $y(\theta)$ units of permits. The permits are remitted once production takes place. Permits can be traded. The (equilibrium) price of permits in terms of the numeraire is denoted by $\phi$. The sequence of events for the producing firms is as follows:

1. Receive shock $\theta$ and plan to produce $q$.

2. Reduce emissions to $y(\theta) \leq \theta q$.

3. Produce and earn profit $f(q)-w q-h(\theta q-y(\theta))$.

4. Adjust permits in the market and remit $y(\theta)$ permits.

5. Profits, if any, are redistributed to shareholders.

6. Next period begins.

We assume that the total stock of emission permits in this economy is $M$, while a firm's individual permit holdings are denoted by $m$. We proceed by defining the firm's problem recursively. We denote the value function of a firm entering the market with $m$ permits and shock $\theta$ by $V(m ; \theta)$. This is defined by

$$
\begin{aligned}
V(m ; \theta) & =\max _{q, y, m_{+}} f(q)-w q-h(\theta q-y)+\phi\left(m-y-m_{+}\right)+\beta E_{\theta} V\left(m_{+}+T ; \theta\right) \\
\text { s.t. } 0 & \leq y \leq \theta q
\end{aligned}
$$

where $T$ is a transfer of permits by the issuing authority. ${ }^{8}$ As we mentioned before, $T$ cannot depend on the individual $\theta$ 's, as they are assumed to be private information. When a firm enters the market for permits, the value of its portfolio is $\phi m$. The firm then has to remit $y$ permits (with value $\phi y)$ and decides how many permits to carry over to the next period, $m_{+}$. As a consequence, the firm's profit changes by the amount $\phi\left(m-y-m_{+}\right)$. Given $M$, the market clearing conditions for permits and goods are

$$
\begin{aligned}
\int y(\theta)+m_{+}(\theta) d G(\theta) & =M \\
\int f(q(\theta))-h(\theta q(\theta)-y) d G(\theta) & =c
\end{aligned}
$$

${ }^{8}$ Note that $T$ is not restricted in sign. 
The law of motion for the stock of permits is

$$
M_{+}=M-\int y(\theta) d G(\theta)+T
$$

Given a policy $\left\{T_{t}\right\}$, an equilibrium is a list of prices, $\left\{\phi_{t}\right\}$, a list of quantities and emissions, $\left\{c_{t}, q_{t}(\theta), y_{t}(\theta)\right\}$, and trading decisions, $\left\{m_{t}(\theta)\right\}$, such that, given prices, the decision variables solve the firms' and the consumers' problems and markets clear. An equilibrium is stationary whenever the list of quantities and emissions is time independent; i.e., $\left\{c_{t}, q_{t}(\theta), y_{t}(\theta)\right\}=$ $\{c, q(\theta), y(\theta)\}$, for all $t$. We first solve the firm's problem. The first order conditions give

$$
\begin{aligned}
f^{\prime}(q)-\theta h^{\prime}(\theta q-y) & =w-\theta \phi \lambda_{\theta}(\theta) \\
h^{\prime}(\theta q-y)-\phi-\phi \lambda_{\theta}(\theta)+\phi \lambda_{0}(\theta) & =0 \\
\beta E_{\theta} V_{m}\left(m_{+}+T ; \theta\right) & \leq \phi=\text { if } m_{+}>0
\end{aligned}
$$

where $\phi \lambda_{\theta}(\theta), \phi \lambda_{0}(\theta)$ are the multipliers on the firm's constraints. Notice that, as there is no persistence, all firms will exit the market for permits with the same amount of permits for the next period. The envelope condition gives

$$
V_{m}(m ; \theta)=\phi
$$

Using this expression in (17) we obtain that $\beta E_{\theta} \phi_{+} \leq \phi$, with equality if firms carry permits from one period to the next. As $\phi_{+}$does not depend on $\theta$, this gives us

$$
\beta \phi_{+} \leq \phi\left(=\text { if } m_{+}>0\right)
$$

In words, firms are willing to "bank" permits, provided that their appropriately discounted future price equals today's spot price. If today's spot price is higher, then firms prefer to buy their permits tomorrow, and no permits are held across periods. This will be the case if the issuing authority is supplying enough permits in the market tomorrow. However, there is no equilibrium if today's spot price is lower, as firms will try to purchase an infinite amount of permits today to resell in tomorrow's market.

Like before, the worker's decision is given by (4) and, using market clearing, we obtain the following expression for the equilibrium wage.

$$
w u^{\prime}\left(\int f(q(\theta))-h(\theta q(\theta)-y(\theta)) d G(\theta)\right)=1 .
$$

To solve for $y(\theta)$, first notice that all firms will reduce their ex-post emissions whenever permits are costly to acquire. In addition, the more costly permits, the more firms choose not to pollute ex-post. The choice of production levels depends only on the realized marginal cost of emissions. It can be shown that $q(\theta, w)$ is decreasing in $\theta$ and in $w$, and that $\bar{\theta}^{\prime}(\phi)>0$.

It is worth mentioning one effect of general equilibrium analysis. The market solution for $q(\theta)$ does not necessarily coincide with the efficient level, $q^{*}(\theta)$. Indeed, notice that if a positive measure of firms do not follow the social planner's production plan, the wage, given by (20), is distorted and so is the decision of firms with $y(\theta)=0$. 
For relatively "dirty" firms, we obtain the following characterization. Dirtier firms reduce emissions by the same amount; i.e., the difference between ex-ante and ex-post emissions is the same. Dirtier firms have higher ex-post emissions, but ex-post emissions decline as permits become more expensive to acquire. The production of dirtier firms declines in the wage, their degree of dirtiness, $\theta$, and in the price of permits. Interestingly, the higher the price of permits, the lower the wage. If permits are more costly to acquire, more firms decide to spend resources to reduce their ex-ante emissions. Those firms who still emit ex-post also reduce their production scale. Therefore, they do not employ as much labor as when the price of permits is low. As a result, the wage has to fall.

The equilibrium price level is, of course, a function of the policy on permit issue, $T$. As expected, if there is a high volume of permits in circulation, they will have no market value. Firms receive a transfer of permits, $T$, in each period, and they are not forced to carry permits from one period to the next. One way to achieve the efficient level of production, $q^{*}(\theta)$, is to set $M$ and $T$ such that $M=T=\int y^{*}(\theta) d G(\theta)=E^{*}$, so that the stock of permits is just sufficient to cover the efficient amount of emissions, $E^{*}$. In this case, the unique equilibrium price, $\phi$, is $\phi=1 / u^{\prime}\left(c^{*}\right)$, and $m_{+}=0$, as $\beta \phi_{+}<\phi$. Thus, there is no banking of permits. In a stationary economy, where the distribution of emissions is the same in each period, this implies that the stock of permits should be set at $E^{*}$. This discussion is summarized in the following.

Proposition 1 (a) Suppose $T \geq \bar{q} \int \theta d G(\theta)$. Then $\phi=0$ and $q(\theta)=\bar{q}$, for all $\theta$. (b) The equilibrium with permits is efficient if $M=T=E^{*}$ for all $t$. The banking of permits is not necessary for efficiency.

Proof. (a) Since $T \geq \bar{q} \int \theta d G(\theta)$, we have that $M \geq \bar{q} \int \theta d G(\theta)$ in all periods. We first guess that $m_{+}=0$ and show that this is the only outcome consistent with equilibrium. Denote by $y(\theta, \phi)$, the choice of emissions by a firm with shock $\theta$, given that the price of permits is $\phi$. Using $m_{+}=0$ in the market clearing condition for permits, we obtain that $M=\int y(\theta, \phi) d G(\theta)$. We have shown that $y(\theta, \phi)$ is a decreasing function of $\phi$, for all $\theta$. Thus, $y(\theta, \phi) \leq y(\theta, 0)=\theta \bar{q}$. But since $M \geq \bar{q} \int \theta d G(\theta)$, the equality $M=\int y(\theta, \phi) d G(\theta)$ cannot hold. Hence, the only equilibrium is when $\phi=0$ and $q(\theta)=\bar{q}$. (19) then implies that $\phi_{+}=0$, thus, $m_{+}=0$.

(b) Using the fact that $\lambda_{\theta}(\theta)=0$, for all $\theta$, the firm's first order condition can be re-arranged as

$$
\begin{gathered}
{\left[f^{\prime}(q)-\theta h^{\prime}(\theta q-y)\right] u^{\prime}(c)=1} \\
h^{\prime}(\theta q-y)=\phi\left[1-\lambda_{0}(\theta)\right]
\end{gathered}
$$

Setting $M=E^{*}$, equilibrium implies that $y=y^{*}(\theta), q=q^{*}(\theta)$, and $\phi$ satisfies $\phi u^{\prime}\left(c^{*}\right)=1$. Indeed, given this $\phi$, we can define $\lambda_{0}(\theta)=\lambda_{0}$, where $\lambda_{0}$ is the multiplier in (10). Then the firm's FOC and the planner's FOC coincide. Therefore, $M=E^{*}$ implements the efficient allocation. ${ }^{9}$

Next, we investigate the implications of taxing emissions. Here we assume that, while the government does not observe $\theta$, ex post emissions, $y(\theta)$, are verifiable, so the government can

\footnotetext{
${ }^{9}$ In the Appendix we show that the structure of the equilibrium does not change if the issuing authority sells permits instead of simply distributing them as transfers. These two methods are essentially the same for our purposes.
} 
impose a tax, $\tau$, on emissions once production takes place. For simplicity, we assume the tax schedule is history-independent, so that $\tau_{t}\left(y \mid h_{t}\right)=\tau_{t+1}\left(y \mid h_{t+1}\right)$, where $h_{t}$ is the history of emissions up to and including date $t-1$. The tax proceeds are then distributed to consumers as a lump-sum transfer. At the start of a period, a firm which received shock $\theta$ solves the following:

$$
\begin{aligned}
& \max _{q, y} f(q)-w q-h(\theta q-y)-\tau(y) \\
& \text { s.t. } 0 \leq y \leq \theta q
\end{aligned}
$$

The first order conditions are

$$
\begin{array}{r}
f^{\prime}(q)-w-\theta h^{\prime}(\theta q-y)=0 \\
h^{\prime}(\theta q-y)-\tau^{\prime}(y)+\tilde{\lambda}_{0}-\tilde{\lambda}_{\theta}=0
\end{array}
$$

The planner's first order conditions are

$$
\begin{aligned}
{\left[f^{\prime}(q(\theta))-\theta h^{\prime}(\theta q-y)\right] u^{\prime}\left(c^{*}\right) } & =1 \\
h^{\prime}(\theta q-y(\theta)) u^{\prime}\left(c^{*}\right)+\lambda_{0}-\lambda_{\theta} & =1
\end{aligned}
$$

It is then easy to see that the tax schedule $\tau(e)=\frac{e}{u^{\prime}\left(c^{*}\right)}$ implements the efficient allocation. Thus, taxes can be an effective way to implement the first-best.

So far we have assumed that there is no aggregate risk. As a result, the optimal levels of production and emissions are known. However, our results generalize to the case where the function $G$ is random. In that case, $c^{*}$ will be a function of $G$, which is not observable. Yet, both cap and trade and a state-contingent tax can support the efficient levels of output and emissions in our economy.

To illustrate, consider the case where emissions are drawn from a new distribution $G_{1}$ instead of the initial distribution $G_{0}$, where $\int \theta d G_{1}(\theta)<\int \theta d G_{0}(\theta)$. In words, firms are on average cleaner and, as a result, $E^{*}$ decreases, from $E_{0}^{*}$ to $E_{1}^{*}<E_{0}^{*}$. Clearly, a tax system which does not depend on any aggregate variable will not achieve the first best. Let us, however, consider a tax system that is measurable with respect to the wage level, $w$, which is observable at the time of production. Then a firm emitting $y$ has to pay $\operatorname{tax} \tau(e ; w)$. Given $G_{i}$, let $c_{i}^{*}$ be the planner's solution for consumption, and let $w_{i}$ be such that $w_{i} u^{\prime}\left(c_{i}^{*}\right)=1$. Define a (state-dependent) tax schedule, $\tau(e ; w)$, as follows:

$$
\tau\left(e ; w_{i}\right)=\frac{e}{u^{\prime}\left(c_{i}^{*}\right)}=e w_{i}
$$

The same analysis as before can be used to show that this tax schedule implements the first-best.

We now turn to cap-and-trade. Under the initial distribution $G_{0}$, efficient emissions are given by $E_{0}^{*}$, and, as we have shown, efficiency results under permit supply $M_{0}=E_{0}^{*}$ and equilibrium price $\phi_{0}$. Now suppose the distribution changes to $G_{1}$. If nothing else changes, the new resulting permit price will decline, signaling to the authority that $G$ has changed to $G_{1}$, in which case the efficient emissions are given by $E_{1}^{*}$. It can be shown that $E_{1}^{*}$ can be supported under permit supply $M_{1}=E_{1}^{*}$, with a resulting equilibrium price $\phi_{1}$, where $\phi_{1}<\phi_{0}$.

In summary, both taxes and emission trading can support the efficient allocation under aggregate risk. This conclusion relies on considering state-contingent taxes. In the case of cap and 
trade, the market price for permits acts as a signalling device. It declines when firms are on average cleaner. However, without a change in the supply of permits, total emissions will diverge from their efficient level. This calls for an authority that can adjust the stock of permits in order to support the new efficient level of emissions. Our analysis suggests that the supply of permits should be a policy variable for this authority, much like the supply in the money market is controlled by a central bank.

\section{Endogenous Technological Change}

Our analysis so far has abstracted from issues related to technological change. These issues are of first-order importance, and our main focus is the study of the relative merits of taxes versus cap and trade if the possibility of endogenous technological change is introduced. ${ }^{10}$ In this section we extend our basic model to account for this possibility.

Like before, we identify firms by their type, $\theta$, indicating their tendency to pollute. Here we assume that types, which remain private information, are distributed at $t=0$ according to a cumulative distribution $G$ with support $[0, \bar{\theta}]$. As in the previous section, a $\theta$-firm emits $\theta q$ units of pollution whenever it uses $q$ units of labor. In this section, we assume that firms can hire labor in order to invent/adopt new, cleaner technologies. To capture the fact that returns to R\&D involve an element of randomness, we assume that a $\theta$-firm can devote $\gamma$ units of labor in order to enter a "lottery." In that case, in the next period, it will receive the new emission factor $\tilde{\theta}=0$ with probability $s$ while, with probability $1-s$, its emission factor remains the same as before $(\tilde{\theta}=\theta)$. In words, with probability $s$ a firm becomes clean forever and with probability $1-s$ it remains as dirty as before. Other than this feature, the model remains the same as in the previous section. ${ }^{11}$

We will consider the simplest case, where $G(\theta)$ has a two-point support, $\{0, \bar{\theta}\}$, with $G(0)=\mu$ denoting the mass of clean firms. ${ }^{12}$ The distribution of firms in every period is summarized by the mass of clean firms, which greatly simplifies the analysis. As in the previous section, our efficiency benchmark will be the full-information first-best. This involves choosing non-negative consumption, $c$, production, $q(\theta)$, and a choice of $R \mathscr{E} D$ investment, $i(\theta) \in[0,1]$, for each firm. Clearly, the efficient allocation would involve no investment in a new technology for clean firms, so we let $i(\bar{\theta}) \in[0,1]$ be the mass of dirty firms entering the lottery. Given that a firms needs to use $\gamma$ units of labor to enter the lottery, the consumers' utility is reduced by the amount of labor devoted to research and development $(1-\mu) \gamma i{ }^{13}$ We denote by $V$ the social planner's objective function, given the initial distribution of clean firms, $\mu$. To reduce notation, in what follows we use $i=i(\bar{\theta}), q=q(0), \bar{q}=q(\bar{\theta})$, while $\mu_{+}=\mu+(1-\mu)$ si $(\bar{\theta})$ denotes the measure of clean firms

\footnotetext{
${ }^{10}$ See Acemoglu, Aghion, Bursztyn, and Hemous (2012) for a discussion of these issues in connection to the environment and growth.

${ }^{11}$ Note that if a firm becomes clean, it remains clean forever. This specification will result in a non-stationary equilibrium fraction of clean firms.

${ }^{12}$ Normalizing the lowest state to $\theta=0$ is only for simplicity and the results generalize to any finite support. Analyzing the case of a continuous support poses technical difficulties and is beyond the scope of this paper.

${ }^{13}$ We assume that R\&D itself is not a polluting activity.
} 
in the next period. The efficient allocation is the solution to the following problem.

$$
\begin{aligned}
V(\mu) & =\operatorname{Max}_{c, q, \bar{q}, i} u(c)-\mu q-(1-\mu)(1+\bar{\theta}) \bar{q}-(1-\mu) \gamma i+\beta V(\mu+(1-\mu) s i) \\
\text { s.t. } \quad c & =\mu f(q)+(1-\mu) f(\bar{q}) \\
0 & \leq i \leq 1
\end{aligned}
$$

Given the linearity of the objective in $i$, we can obtain an explicit form for $V(\mu)$. Notice first that the solution for $c, q$, and $\bar{q}$ does not depend on $i$. Replacing the market clearing condition in the planner's objective and taking the first order conditions with respect to $q$ and $\bar{q}$, we obtain

$$
\begin{aligned}
& u^{\prime}(\mu f(q)+(1-\mu) f(\bar{q})) f^{\prime}(q)=1 \\
& u^{\prime}(\mu f(q)+(1-\mu) f(\bar{q})) f^{\prime}(\bar{q})=1+\bar{\theta}
\end{aligned}
$$

Given $\mu$, define the solution by $q^{*}(\mu)$ and $\bar{q}^{*}(\mu)$. Plugging these values in the market clearing condition determines $c^{*}(\mu)$. Thus, the planner's problem becomes

$$
\begin{aligned}
& V(\mu)=\max _{i} F(\mu)-(1-\mu) \gamma i+\beta V(\mu+(1-\mu) s i) \\
& \text { s.t. } 0 \leq i \leq 1
\end{aligned}
$$

where $F(\mu) \equiv u\left(c^{*}(\mu)\right)-\mu q^{*}(\mu)-(1-\mu)(1+\bar{\theta}) \bar{q}^{*}(\mu)$. As the solution to (29) and (30) is unique, there is a single value of $\mu$ such that $F(\mu)=v$, for each value of the instantaneous surplus $v$. Also, $F$ is differentiable with

$$
\left.F^{\prime}(\mu)=u^{\prime *}(\mu)\right)\left[f\left(q^{*}(\mu)\right)-f\left(\bar{q}^{*}(\mu)\right)\right]-q^{*}(\mu)+(1+\theta) \bar{q}^{*}(\mu)
$$

and $\left.F^{\prime \prime}(\mu)=u^{\prime \prime *}(\mu)\right)\left[f\left(q^{*}(\mu)\right)-f\left(\bar{q}^{*}(\mu)\right)\right] c^{\prime}(\mu)<0$. Our assumptions on preferences and technology guarantee that $F^{\prime-1}$ exists. Let $\Phi \equiv F^{\prime-1}\left(\frac{1-\beta}{\beta} \frac{\gamma}{s}\right)$. We now guess that the value function takes the form

$$
V(\mu)=F(\mu)+\frac{\gamma}{s}(\mu-\Phi)+\frac{\beta}{1-\beta} F(\Phi)
$$

To verify, using (33) the planner's problem becomes

$$
\begin{array}{ll}
\max _{i} & F(\mu)-(1-\mu) \gamma i+\beta\left[F(\mu+(1-\mu) s i)+\frac{\gamma}{s}(\mu+(1-\mu) s i)-\frac{\gamma}{s} \Phi+\frac{\beta}{1-\beta} F(\Phi)\right] \\
\text { s.t. } \quad 0 \leq i \leq 1
\end{array}
$$

The first order condition gives

$$
i=\frac{\Phi-\mu}{(1-\mu) s}
$$

Using this policy function in the objective function, we obtain

$$
\begin{aligned}
V(\mu) & =F(\mu)-(1-\mu) \gamma \frac{\Phi-\mu}{(1-\mu) s}+\beta\left[F(\Phi)+\frac{\gamma}{s} \Phi-\frac{\gamma}{s} \Phi+\frac{\beta}{1-\beta} F(\Phi)\right] \\
& =F(\mu)-\frac{\gamma}{s}(\Phi-\mu)+\beta\left[F(\Phi)+\frac{\beta}{1-\beta} F(\Phi)\right] \\
& =F(\mu)+\frac{\gamma}{s}(\mu-\Phi)+\frac{\beta}{1-\beta} F(\Phi)
\end{aligned}
$$


which verifies our guess. Notice that $\Phi$ is a constant in $[0,1]$. From $(35), \frac{\partial i}{\partial \mu}=\frac{-(1-\mu) s+(\Phi-\mu) s}{[(1-\mu) s]^{2}}<0$. Hence, as the measure of clean firms increases, the planner reduces investment in clean technology R\&D. Clearly, there is a $\bar{\mu}$ such that for all $\mu \geq \bar{\mu}$, the planner chooses $i(\bar{\mu})=0$. The threshold level, $\bar{\mu}$, is defined by

$$
\begin{aligned}
\Phi & =\bar{\mu}, \text { or } \\
F^{\prime}(\bar{\mu}) & =\frac{1-\beta}{\beta} \frac{\gamma}{s}
\end{aligned}
$$

If there is no emissions control, firms maximize their profits without concern about emissions, and their production decision follows (2). No firm invests in emissions reduction, as the investment in $\mathrm{R} \& \mathrm{D}$ is costly. Since firms' production decision is independent of their shock, overall emissions (the emissions from dirty firms) are given by $\bar{E}=(1-\mu) \bar{\theta} \bar{q}$, where $\bar{q}$ is the equilibrium level of production. Taking $E$ as given, consumers maximize their utility subject to their budget constraint and their behavior is again summarized by the first order condition (4). Market clearing is given by (5) and the equilibrium level of production $\bar{q}$ satisfies $(6)$; i.e., $f^{\prime}(q) u^{\prime}(f(q))=1$. Welfare in this economy is given by

$$
(1-\beta) W=u(f(\bar{q}))-\bar{q}(1+(1-\mu) \bar{\theta})
$$

We discuss two forms of policy next.

\subsection{Emissions Trading}

We first consider a cap and trade system. A dirty firm producing $q$ and receiving emission factor $\bar{\theta}$, will need to accumulate $\bar{\theta} q$ permits in that period. The permits are then remitted once production takes place. As before, firms can also invest in order to reduce their emissions. There is a market where firms can trade permits. We assume that ex post emissions, $y=\theta q$, are observable, while $\theta$ and $i(\theta)$ are private information. ${ }^{14}$ The price of permits in terms of the numeraire is again denoted by $\phi$. The sequence of events is as follows:

1. Firms of type $\theta \in\{0, \bar{\theta}\}$ plan to produce $q(\theta)$ and invest $i(\theta)$ in R\&D. Firms are able to randomize, so $i(\theta) \in[0,1]$ denotes the probability of investing.

2. Firms produce and earn profit $f(q)-w(q+\gamma I)$, where $I \in\{0,1\}$ is the result of the lottery $i(\theta)$.

3. Firms adjust their permits in the market and remit $\theta q$ permits.

4. Profits, if any, are redistributed to shareholders.

5. Firms learn the result of their R\&D investment and move to the next period.

\footnotetext{
${ }^{14}$ Assuming that ex post emissions are observable might seem strong. However, this strengthens our conclusion as we will demonstrate that a tax scheme will be more effective even if emissions trading can condition on such expanded information.
} 
As before, we denote the total stock of permits in this economy by $M$, while a firm's individual permit holdings are denoted by $m$. We denote the value of a dirty firm entering the market with $m$ permits and shock $\bar{\theta}$ by $V_{\bar{\theta}}(m)$, and the value of a corresponding clean firm by $V_{0}(m)$. Hence, $V_{\theta}(m)$ for $\theta \in\{0, \bar{\theta}\}$ is defined by ${ }^{15}$

$$
\begin{aligned}
V_{\theta}(m)= & \max _{q, i, m_{+}^{0}, m_{+}^{\theta}} f(q)-w(q+\gamma i)+\phi m-\phi \theta q \\
& +i s\left[-\phi m_{+}^{0}+\beta V_{0}\left(m_{+}^{0}+T_{+}^{0}\right)\right]+[i(1-s)+(1-i)]\left[-\phi m_{+}^{\theta}+\beta V_{\theta}\left(m_{+}^{\theta}+T_{+}^{y}\right)\right] \\
\text { s.t. } 0 \leq & i \leq 1
\end{aligned}
$$

where $T_{+}^{y}$ is the (ex-post emissions-dependent) transfer of permits by the issuing authority. When a firm enters the market for permits, the value of its portfolio is $\phi m$. The firm then has to remit $\theta q$ permits (of value $\phi \theta q$ ) and decides how many permits to carry over to the next period, $m_{+}$. The first order conditions for an interior condition $i(\theta) \in(0,1)$ are

$$
\begin{gathered}
f^{\prime}-w-\phi \theta=0 \\
-w \gamma+s\left[-\phi m_{+}^{0}+\beta V_{0}\left(m_{+}^{0}+T^{0}\right)\right]-s\left[-\phi m_{+}^{\theta}+\beta V_{\theta}\left(m_{+}^{\theta}+T_{+}^{y}\right)\right] \leq 0 \\
(=\text { if } i>0,>0, \text { if } i=1) \\
-\phi+\beta V_{0}^{\prime}\left(m_{+}^{0}+T_{+}^{0}\right) \leq 0\left(=\text { if } m_{+}^{0}>0\right) \\
-\phi+\beta V_{\theta}^{\prime}\left(m_{+}^{\theta}+T_{+}^{y}\right) \leq 0\left(=\text { if } m_{+}^{\theta}>0\right)
\end{gathered}
$$

and the envelope condition gives $V_{\theta}^{\prime}(m)=\phi$, for $\theta \in\{0, \bar{\theta}\}$. The first order condition for $i(0)$ clearly implies that $i(0)=0$, as clean firms remain clean. The last two conditions imply that, in an equilibrium with banking, the price of permits must satisfy

$$
\phi=\beta \phi_{+}
$$

The consumer's first order conditions give

$$
w u^{\prime}(c)=1
$$

Finally, market clearing implies

$$
\begin{aligned}
\mu f\left(q^{0}\right)+(1-\mu) f\left(q^{\bar{\theta}}\right) & =c \\
\mu m_{+}^{0}+(1-\mu) m_{+}^{1} & =M+T
\end{aligned}
$$

and the law of motion for clean firms is $\mu_{+}=\mu+s i(\bar{\theta})(1-\mu)$. Next, we determine whether the efficient allocation is implementable. We divide the analysis into three cases. First we discuss the policies which implement the efficient allocation when $\mu \geq \bar{\mu}$ and when $\mu<\bar{\mu}$, but close to $\bar{\mu}$. Finally, we consider the case where $\mu$ is far below $\bar{\mu}$.

(i) Case when $\mu \geq \bar{\mu}$

\footnotetext{
${ }^{15}$ To economize on notation, we suppress the dependence on $\mu$ in what follows.
} 
First, note that the equilibrium outcome in an economy with banking but without transfers is inefficient for all $\mu \geq \bar{\mu}$. Indeed, in this case the efficient allocation is such that $q(\bar{\theta})$ satisfies $w f^{\prime}(\bar{q})=1+\bar{\theta}$, where $w=u^{\prime}(c)^{-1}$. But this can only be the case if $\phi=w$. Therefore, $\phi>$ $\beta \phi_{+}=\beta \phi$, which contradicts efficiency. The only other way to reach the efficient allocation when $\mu \geq \bar{\mu}$ is through the use of a transfer policy $T_{t}^{y} \geq 0$. With $\mu \geq \bar{\mu}$, a transfer policy is optimal only if (29) and (30) are satisfied. Now, (40) together with (45) and (46) imply that $\phi=w(\mu)=u^{\prime}\left(\mu f\left(q^{0}\right)+(1-\mu) f\left(q^{\bar{\theta}}\right)\right)^{-1}$, for all $t$. Hence, $T_{t}^{y}$ must satisfy

$$
V_{\theta}^{\prime}\left(T_{t}^{y}\right)=\phi=w(\mu)
$$

Thus, $T_{t}^{y}=T^{y}$, a constant, and market clearing requires $T^{y}=\bar{\theta} q$. Hence, dirty firms should not conduct $\mathrm{R} \& \mathrm{D}$ whenever $\mu \geq \bar{\mu}$, and the transfer should implement $i(\bar{\theta})=0$. That is,

$$
V_{0}(0)-V_{\theta}\left(T^{y}\right)<\frac{\gamma w}{\beta s}
$$

where

$$
V_{0}(0)-V_{\theta}\left(T^{y}\right)=\frac{f\left(q^{0}\right)-w q^{0}}{1-\beta}-\frac{f\left(q^{\bar{\theta}}\right)-w q^{\bar{\theta}}-w \bar{\theta} q^{\bar{\theta}}+w T^{y}}{1-\beta}
$$

Using the market clearing condition in the market for permits, we obtain that $i(\bar{\theta})=0$ if

$$
f\left(q^{0}\right)-w q^{0}-\left[f\left(q^{\bar{\theta}}\right)-w q^{\bar{\theta}}\right]<(1-\beta) \frac{\gamma w}{\beta s}
$$

Since $\mu \geq \bar{\mu}$ and $F^{\prime \prime}<0$, this condition is satisfied since $f\left(q^{0}\right)-w q^{0}-\left[f\left(q^{\bar{\theta}}\right)-w q^{\bar{\theta}}\right]<w F^{\prime}(\bar{\mu})$ which is equal to $(1-\beta) \frac{\gamma w}{\beta s}$ by $(37)$.

(ii) Case when $\mu<\bar{\mu}$ but close to $\bar{\mu}$

In this case, the efficient allocation has some dirty firms investing in R\&D. Therefore, it must be that (41) holds with equality, or,

$$
\left[-\phi m_{+}^{0}+\beta V_{0}\left(m_{+}^{0}+T_{+}^{0}\right)\right]-\left[-\phi m_{+}^{\theta}+\beta V_{\theta}\left(m_{+}^{\theta}+T_{+}^{y}\right)\right]=\frac{w \gamma}{s}
$$

We can then write $V_{\theta}(m)$ as

$$
\begin{aligned}
V_{\theta}(m)= & \max _{q, i, m_{+}^{0}, m_{+}^{\theta}} f(q)-w(q+\gamma i)+\phi m-\phi \theta q \\
& +i s \frac{w \gamma}{s}-\phi m_{+}^{0}+\beta V_{0}\left(m_{+}^{0}+T_{+}^{0}\right)-\frac{w \gamma}{s} \\
\text { s.t. } 0 \leq & i \leq 1
\end{aligned}
$$

or, using the solution for $q^{0}$ for clean firms,

$$
\begin{aligned}
V_{\theta}(m)= & \max _{q, i, m_{+}^{0}, m_{+}^{\theta}} f(q)-w q+\phi m-\phi \theta q \\
& -f\left(q^{0}\right)-\phi m^{0}+w q^{0}+V_{0}\left(m^{0}\right)-\frac{w \gamma}{s}
\end{aligned}
$$


We need to check whether we can obtain (51) using this formulation. Let $q^{\theta}$ be the solution to the dirty firm's problem given wage $w$. Then

$$
V_{\theta}(m)-V_{0}\left(m^{0}\right)=f\left(q^{\theta}\right)-f\left(q^{0}\right)-w q^{\theta}-\phi \theta q^{\theta}+w q^{0}+\phi\left(m-m^{0}\right)-\frac{w \gamma}{s}
$$

Using this expression into $(51)$, we obtain that $i(\bar{\theta}) \in(0,1)$ iff

$\frac{w \gamma}{s}=\left(\beta w_{+}-w\right)\left(m_{+}^{0}-m_{+}^{\theta}\right)+\beta\left[f\left(q_{+}^{0}\right)-f\left(q_{+}^{\theta}\right)-w_{+} q_{+}^{0}+w_{+}(1+\theta) q_{+}^{\theta}+w_{+}\left(T_{+}^{0}-T_{+}^{y}\right)+\frac{w_{+} \gamma}{s}\right]$

where we have used that $\phi_{+}=w_{+}$, as this is a necessary condition for efficiency. Using $F^{\prime}\left(\mu_{+}\right)$, we can rewrite the above equation as

$$
\left(\beta-\frac{w}{w_{+}}\right) s\left(m_{+}^{0}-m_{+}^{\theta}\right)+\beta\left[s F^{\prime}\left(\mu_{+}\right)+s\left(T_{+}^{0}-T_{+}^{y}\right)+\gamma\right]=\frac{w}{w_{+}} \gamma
$$

Comparing this equation with (35) the efficient outcome with $i=i^{*}$ is implemented iff

$$
\left(\beta-\frac{w}{w_{+}}\right) s\left(m_{+}^{0}-m_{+}^{\theta}\right)+\beta s\left(T_{+}^{0}-T_{+}^{y}\right)+\beta \gamma-\frac{w}{w_{+}} \gamma=-\gamma+\beta \gamma
$$

or

$$
\beta s\left(T_{+}^{0}-T_{+}^{y}\right)=\left(\frac{w}{w_{+}}-1\right) \gamma+\left(\frac{w}{w_{+}}-\beta\right) s\left(m_{+}^{0}-m_{+}^{\theta}\right)
$$

Since $\phi_{+}=w_{+}$, the consumers' first order condition gives $u^{\prime}(c)=w(\mu)^{-1}$. Thus,

$$
\frac{\beta \phi_{+}}{\phi}=\beta \frac{u^{\prime}(c(\mu))}{u^{\prime}\left(c\left(\mu_{+}\right)\right)}<1
$$

where the last inequality follows from the assumption that $\mu$ is close to $\bar{\mu}$. In this case, the efficient allocation implies that investment in R\&D decreases (so that $\mu$ can be close to $\mu_{+}$) in order to satisfy the above inequality. In that case, $m_{+}^{0}=m_{+}^{\theta}=0$, so that (58) gives

$$
T^{y}\left(\mu_{+}\right)=\left(1-\frac{u^{\prime}\left(c\left(\mu_{+}\right)\right)}{u^{\prime}(c(\mu))}\right) \frac{\gamma}{\beta s}+T^{0}\left(\mu_{+}\right)
$$

Market clearing requires that

$$
(1-\mu) T^{y}(\mu)+\mu T^{0}(\mu)=(1-\mu) \theta q^{\theta}
$$

Therefore,

$$
\begin{aligned}
& T^{0}\left(\mu_{+}\right)=\left(1-\mu_{+}\right) \theta q_{+}^{\theta}-\left(1-\mu_{+}\right)\left(1-\frac{u^{\prime}\left(c\left(\mu_{+}\right)\right)}{u^{\prime}(c(\mu))}\right) \frac{\gamma}{\beta s} \\
& T^{y}\left(\mu_{+}\right)=\left(1-\mu_{+}\right) \theta q_{+}^{\theta}+\mu_{+}\left(1-\frac{u^{\prime}\left(c\left(\mu_{+}\right)\right)}{u^{\prime}(c(\mu))}\right) \frac{\gamma}{\beta s}
\end{aligned}
$$


Notice that if $\mu_{+}$is close enough to $\mu$ (which will be the case when $i(\theta)$ is sufficiently close to zero), then $T^{0}(\mu)>0$, so that the optimal policy is to grant some permits to clean firms. As $T^{y}(\mu)$ is not sufficient for dirty firms to pledge the required permits, they will have to purchase the missing permits from clean firms, thus, effectively subsidizing them. This subsidy makes being "clean" more attractive and incentivizes investment in R\&D. Note that this is in addition to having to give up revenue from permits. This additional incentive is necessary since efficiency requires that $w=\phi$.

(iii) Case when $\mu$ is far lower than $\bar{\mu}$

Finally, we consider the case where $\mu$ is far lower than $\bar{\mu}$, so that $u^{\prime *}\left(c\left(\mu_{+}\right)\right) / u^{\prime *}(c(\mu))<\beta$. Emissions trading cannot implement the efficient allocation in this case. Indeed, optimality requires that $w(\mu)=\phi(\mu)$ and $w(\mu) u^{\prime}(c(\mu))=1$. But this would imply that $\phi(\mu)<\beta \phi\left(\mu_{+}\right)$. This is not consistent with an equilibrium, as it implies an excess demand of permits by firms who will want to resell them in the next period. It is useful to provide some intuition for this result. Efficiency requires that aggregate $i$ increases fast. To induce this increase, the future price of permits must be sufficiently high. However, this creates an incentive for firms to purchase permits now, in order to sell them in the future, when the price will be higher. This is inconsistent with equilibrium, as it creates an excess demand for permits.

In summary, when the measure of dirty firms is greater than a critical threshold, the efficient allocation is not implementable via the use of an emissions trading system. Equilibrium under emissions trading either makes technology adoption by dirty firms too slow, or it distorts production by dirty firms relative to the first best. Below we show that fiscal policies do not suffer from this drawback. As in the case without endogenous technology change, a tax scheme can always implement the first best.

\subsection{Taxes}

We denote the value of a dirty firm by $V_{\bar{\theta}}$, and the value for a clean firm by $V_{0}$. Hence, for $\theta \in\{0, \bar{\theta}\}, V_{\theta}$ is defined by

$$
\begin{aligned}
V_{\theta}(\mu)= & \max _{q, i} f(q)-w(q+\gamma i)-\tau(\theta q \mid \mu) \\
& +i s \beta V_{0}\left(\mu_{+}\right)+[i(1-s)+(1-i)] \beta V_{\theta}\left(\mu_{+}\right) \\
\text {s.t. } 0 \leq & i \leq 1
\end{aligned}
$$

The first order conditions are

$$
\begin{aligned}
f^{\prime}-w-\theta \tau^{\prime}(\theta q \mid \mu) & =0 \\
-w \gamma+s \beta V_{0}\left(\mu_{+}\right)-s \beta V_{\theta}\left(\mu_{+}\right) & \leq 0(=0, \text { if } i>0,>0, \text { if } i=1)
\end{aligned}
$$

Clearly, optimality requires that

$$
\tau^{\prime}(\theta q \mid \mu)=w(\mu)
$$

so that the optimal tax is linear in the quantity of emissions; i.e., $\tau(\theta q \mid \mu)=w(\mu) \theta q+x^{\theta}(\mu)$, for some $x^{\theta}(\mu)$. To induce investment, the tax must be such that (66) holds with equality whenever 
$i^{*}>0$. Using this and $q^{0}$ (the optimal choice of clean firms), we can rewrite $V_{\bar{\theta}}(\mu)$ as

$$
V_{\bar{\theta}}(\mu)=\max _{q} f(q)-w q-\tau(\theta q \mid \mu)-\left[f\left(q^{0}\right)-w q^{0}-\tau(0 \mid \mu)\right]+V_{0}(\mu)-w \gamma / s
$$

Therefore,

$$
V_{\bar{\theta}}\left(\mu_{+}\right)-V_{0}\left(\mu_{+}\right)=f\left(q_{+}^{\theta}\right)-w\left(\mu_{+}\right) q_{+}^{\theta}-\tau\left(\theta q_{+}^{\theta} \mid \mu_{+}\right)-\left[f\left(q_{+}^{0}\right)-w\left(\mu_{+}\right) q_{+}^{0}-\tau\left(0 \mid \mu_{+}\right)\right]-w\left(\mu_{+}\right) \gamma / s
$$

Using this expression back in $(66)$, we obtain that $i^{*} \in(0,1)$ iff

$$
\begin{gathered}
V_{0}\left(\mu_{+}\right)-V_{\theta}\left(\mu_{+}\right)=\frac{w(\mu) \gamma}{s \beta} \\
{\left[f\left(q_{+}^{0}\right)-w\left(\mu_{+}\right) q_{+}^{0}-x^{0}\left(\mu_{+}\right)\right]-\left[f\left(q_{+}^{\theta}\right)-w\left(\mu_{+}\right) q_{+}^{\theta}-w\left(\mu_{+}\right) \theta q_{+}^{\theta}-x^{\theta}\left(\mu_{+}\right)\right]+\frac{w\left(\mu_{+}\right) \gamma}{s}=\frac{w(\mu) \gamma}{s \beta}} \\
s \beta F^{\prime}\left(\mu_{+}\right)+\beta \gamma-s \beta \frac{x^{0}\left(\mu_{+}\right)-x^{\theta}\left(\mu_{+}\right)}{w\left(\mu_{+}\right)}=\frac{w(\mu) \gamma}{w\left(\mu_{+}\right)}
\end{gathered}
$$

Comparing this last expression with (35), we obtain that the tax policy can implement $i^{*}$ iff

$$
s \beta \frac{x^{0}\left(\mu_{+}\right)-x^{\theta}\left(\mu_{+}\right)}{w\left(\mu_{+}\right)}=\left[1-\frac{w(\mu)}{w\left(\mu_{+}\right)}\right] \gamma
$$

or, using the consumers' first order condition, iff

$$
x^{0}\left(\mu_{+}\right)-x^{\theta}\left(\mu_{+}\right)=\frac{1}{u^{\prime}\left(c\left(\mu_{+}\right)\right)}\left[1-\frac{u^{\prime}\left(c\left(\mu_{+}\right)\right)}{u^{\prime}(c(\mu))}\right] \frac{\gamma}{s \beta}
$$

In particular, if $x^{0}=0$, then $x^{\theta}(\mu)<0$ and dirty firms should receive a corresponding lump-sum subsidy. We summarize our main finding in the following.

Proposition 2 A tax scheme is less constrained in achieving the optimum than emissions trading. Equilibrium under emissions trading imposes the additional condition that $\phi=w$, which reduces the range of feasible policies. As a result, emissions trading fails to attain the first best when the measure of dirty firms is greater than a critical threshold.

Our overall message is as follows. In monetary models, certain conditions need to be satisfied in order for money to have value in equilibrium. Modeling explicitly the money-like feature of permits in an intertemporal model implies that a set of related requirements must be satisfied in order for permits to have value. We showed that these requirements are likely to be binding in the case where there is endogenous progress in clean technologies and when the initial fraction of "dirty" firms is large. On the other hand, tax policies do not need to satisfy these additional requirements. 


\section{Conclusion}

Our work is motivated by the observation that emission-trading resembles monetary trade. We used insights from dynamic mechanism design in monetary economics to derive properties of optimal dynamic emissions trading mechanisms. More generally, we argued that policy-makers should think about permit-issue in a manner similar to that used by central bankers, and we discussed optimal permit-issue policy. At the optimum, the price of permits increases over time. Our main finding is that when there is endogenous technological progress in clean technologies, and if the measure of dirty firms is large, the efficient allocation is not implementable via the use of an emissions trading system. Equilibrium under emissions trading either makes technology adoption by dirty firms too slow, or it distorts production of dirty firms relative to the first best. We showed that fiscal policies do not suffer from this drawback.

Our model can be extended in several directions. First, while we studied conditions under which the first-best is implementable, we have not characterized the constrained-efficient allocations in the cases when the first-best cannot be supported. As we mentioned already, it would also be interesting to extend the analysis to accommodate serially correlated shocks. Finally, we could study generalizations of the assumed functional forms. As we argued earlier, we made these assumptions mainly for tractability, and we believe our results to be robust under various generalizations of the model. 


\section{References}

[1] Acemoglu, D., P. Aghion, L. Bursztyn, and D. Hemous (2012): "The Environment and Directed Technical Change," American Economic Review, 102(1): 131-66

[2] Albrizio, S., and H. Costa (2012): "Policy Uncertainty and Investment in Low-Carbon Technology," European University Institute Working Paper, ECO 2012/27

[3] Blyth, W., R. Bradley, D. Bunn, C. Clarke, T. Wilson, and M. Yang (2007): "Investment risks under uncertain climate change policy," Energy Policy, 35(11), 5766-5773

[4] Brunner, S., Flachsland, C., and R. Marschinski (2011): "Credible Commitment in Carbon Policy," Climate Policy 12(2), 255-271

[5] Chen, Y., and C.-L. Tseng (2011): "Inducing Clean Technology in the Electricity Sector: Tradable Permits or Carbon Tax Policies?," The Energy Journal, 0(3)

[6] Clï ¡œ S. and \& E. Vendramin (2012): "Is the ETS still the best option? Why opting for a carbon tax," Instituto Bruno Leoni Special Report

[7] Colla, P., M. Germain, and V. Van Steenberghe (2012): "Environmental Policy and Speculation on Markets for Emission Permits," Economica, 79(313), 152-182

[8] Eeckhout J. and P. Kircher (2010): "Sorting vs Screening - Search Frictions and Competing Mechanisms," Journal of Economic Theory, 145, 1354-1385.

[9] Ellerman, A., F. Convery, C. Perthuis, and E. Alberola (2010): Pricing carbon: the European Union Emissions Trading Scheme. Cambridge University Press

[10] Germain, M., V. V. Steenberghe, and A. Magnus (2004): "Optimal Policy with Tradable and Bankable Pollution Permits: Taking the Market 32 Microstructure into Account," Journal of Public Economic Theory, 6(5), 737-757

[11] Golosov, M., N. Kocherlakota, and A. Tsyvinski (2003): "Optimal Indirect and Capital Taxation," Review of Economic Studies, 70, 569-587

[12] Heutel G. (2012): "How Should Environmental Policy Respond to Business Cycles? Optimal Policy Under Persistent Productivity Shocks," Review of Economic Dynamics, 15(2), 244-264

[13] Lackner, K., Wilson, R., and Ziock, H.-J. (2001): "Free Market Approaches to Controlling Carbon Dioxide Emissions to the Atmosphere. In Kursunogammalu, B. N., Mintz, S. L., and Perlmutter, A., Editors, Global Warming and Energy Policy Global Warming and Energy Policy, New York. Springer

[14] Laffont J.-J. and J. Tirole (1996): "Pollution Permits and Environmental Innovation," Journal of Public Economics, 62, 127-140 
[15] Li Z., and Shouyong Shi (2010): "Emission Tax or Standard? The Role of Productivity Dispersion," University of Toronto, Departent of Economics Working Paper 409

[16] Montgomery, W. D. (1972): "Markets in licenses and efficient pollution control programs," Journal of Economic Theory, 5(3), 395-418

[17] Requate T. (2005): "Dynamic Incentives by Environmental Policy Instruments - A Survey," Ecological Economics, 54, 175-195

[18] Wallace N. (2012): "The Mechanism-design Approach to Monetary Economics," forthcoming in The New Handbook of Monetary Economics, edited by Ben Friedman and Michael Woodford

[19] Weitzman M.L. (1972): "Prices vs. Quantities," The Review of Economic Studies, 41(4), 477-491 


\section{Technical Appendix}

Lemma 3 (a) $y(\theta)<\theta q^{*}(\theta)$, for all $\theta$ such that $q^{*}(\theta)>0$; (b) Assume $-f^{\prime \prime}(q) q / f^{\prime}(q) \geq 1$, for all $q$. Then $\partial y^{*}(\theta) / \partial \theta>0$ and there is a $\tilde{\theta}>0$ such that $y(\theta)=0$ for all $\theta<\tilde{\theta}$. In addition, $\theta q^{*}(\theta)-y^{*}(\theta)$ is constant for all $\theta \geq \tilde{\theta}$.

Proof: (a) Suppose that $\lambda_{\theta}>0$, for some $\theta$. Then $y(\theta)=\theta q(\theta)$. As a consequence, $\lambda_{0}=0$, and (10) implies $1=-\lambda_{\theta}<0$, which is a contradiction.

(b) Since $\lambda_{\theta}(\theta)=0$, the first order conditions are

$$
\begin{aligned}
{\left[f^{\prime}\left(q^{*}(\theta)\right)-\theta h^{\prime}\left(\theta q^{*}(\theta)-y^{*}(\theta)\right)\right] u^{\prime}\left(c^{*}\right) } & =1 \\
h^{\prime}\left(\theta q^{*}(\theta)-y^{*}(\theta)\right) u^{\prime}\left(c^{*}\right)+\lambda_{0} & =1
\end{aligned}
$$

First, consider the set of $\theta$ 's for which $\lambda_{0}=0$. Then, $y(\theta) \in(0, \theta q)$, and the first order conditions are

$$
\begin{aligned}
f^{\prime}\left(q^{*}(\theta)\right) u^{\prime}\left(c^{*}\right) & =1+\theta \\
h^{\prime}\left(\theta q^{*}(\theta)-y^{*}(\theta)\right) u^{\prime}\left(c^{*}\right) & =1
\end{aligned}
$$

Given $c^{*},(74)$ implies that $q^{*}(\theta)$ is decreasing with $\theta$. Also (75) implies that

$$
\frac{d y}{d \theta}=q+\theta \frac{d q}{d \theta}=q\left(1+\frac{\theta}{1+\theta} \frac{f^{\prime}}{f^{\prime \prime} q}\right)
$$

so that $y(\theta)$ is increasing in $\theta$ if $-\frac{f^{\prime \prime} q}{f^{\prime}} \geq 1 .{ }^{16}$ Therefore, there is $\tilde{\theta}$ such that given $c^{*}, \lambda_{0}=0$ and $y(\tilde{\theta})=0$. Given $\tilde{\theta}, q(\tilde{\theta})$ solves

$$
\begin{aligned}
f^{\prime}\left(q^{*}(\tilde{\theta})\right) u^{\prime}\left(c^{*}\right) & =1+\tilde{\theta} \\
h^{\prime}\left(\tilde{\theta} q^{*}(\tilde{\theta})\right) u^{\prime}\left(c^{*}\right) & =1
\end{aligned}
$$

In turn, $\tilde{\theta}$ solves

$$
h^{\prime}\left(\tilde{\theta} \Phi\left(\frac{1+\tilde{\theta}}{u^{\prime}\left(c^{*}\right)}\right)\right) u^{\prime}\left(c^{*}\right)=1
$$

where $\Phi(x)=f^{\prime-1}(x)$. For all $\theta>\tilde{\theta}$, the solution is given by (74) and (75). Also, if $\theta<\tilde{\theta}$, it cannot be the case that $\lambda_{0}=0$. Thus, $y(\theta)=0$, for all $\theta<\tilde{\theta}$. Notice that $\theta q^{*}(\theta)-y^{*}(\theta)$ is constant in $\theta$ whenever $y^{*}(\theta)>0$; i.e., the reduction in emissions is the same for all firms. Finally, it remains to show that $\tilde{\theta}>0$. By contradiction suppose that $\tilde{\theta}=0$. Notice that for any $q^{*}(\theta)$ and $y^{*}(\theta)$ satisfying (74) and (75), it must be the case that $q^{*}(\theta)<q^{*}(0)$ and $\theta q^{*}(\theta) \rightarrow 0$, as $\theta \rightarrow 0$. Therefore, $h^{\prime}\left(\theta q^{*}(\theta)-y^{*}(\theta)\right) \rightarrow 0$, as $\theta \rightarrow 0$. Thus, for any $c^{*}$ and $\varepsilon>0$, there is $\theta>0$ such that $h^{\prime}\left(\theta q^{*}(\theta)-y^{*}(\theta)\right)=\varepsilon$ and $\varepsilon u^{\prime}\left(c^{*}\right)<1$. This contradicts that $y(\theta)>0$, implying that $\tilde{\theta}>0$.

\footnotetext{
${ }^{16}$ This is the case, for example, if $f(x)=\ln x$, or if $f(x)=A\left(1-e^{-\alpha x}\right)$, with $\alpha \geq 1$.
} 
Lemma 4 The efficient allocation is such that $\tilde{\theta}_{1}>\tilde{\theta}_{0}$. For all $\theta>\tilde{\theta}_{1}, q_{1}^{*}(\theta)<q_{0}^{*}(\theta)$ and $y_{1}^{*}(\theta)<y_{0}^{*}(\theta)$.

Proof: From (74) and (75), given a level of aggregate consumption, $c^{*}$, the value of $q^{*}(\theta)$, is decreasing in $\theta$ whenever $y(\theta)>0$. Since there is a larger fraction of clean firms in the economy under $G_{1}$ (while the mass of firms is the same), we infer that $c_{1}^{*}>c_{0}^{*}$. In this case, (74) implies that $f^{\prime}\left(q_{1}^{*}\right) u^{\prime}\left(c_{1}^{*}\right)=f^{\prime}\left(q_{0}^{*}\right) u^{\prime}\left(c_{0}^{*}\right)$ whenever $y_{1}^{*}, y_{0}^{*}>0$. Therefore, $q_{1}^{*}(\theta)<q_{0}^{*}(\theta)$; i.e., firms with the same $\theta$ produce relatively less in the cleaner economy. Finally, from (75), $h^{\prime}\left(\theta q_{1}^{*}(\theta)-y_{1}^{*}(\theta)\right) u^{\prime}\left(c_{1}^{*}\right)=h^{\prime}\left(\theta q_{0}^{*}(\theta)-y_{0}^{*}(\theta)\right) u^{\prime}\left(c_{0}^{*}\right)$, so that $\theta q_{1}^{*}(\theta)-y_{1}^{*}(\theta)>\theta q_{0}^{*}(\theta)-y_{0}^{*}(\theta)$. Thus, firms with the same $\theta$ reduce their emissions by a larger factor in the cleaner economy. Next, we demonstrate that $\tilde{\theta}_{1}>\tilde{\theta}_{0}$. First, notice that, for any $c, \theta q(\theta)$ is increasing in $\theta$ if $-f^{\prime \prime} q \geq f^{\prime}$. This implies that, given $c, \theta \Phi\left(\frac{1+\theta}{u^{\prime}(c)}\right)$ is increasing in $\theta$, where $\Phi(x)=f^{\prime-1}(x)$. Second, since $\Phi^{\prime}(x)<0$ and $u^{\prime}\left(c_{1}^{*}\right)<u^{\prime}\left(c_{0}^{*}\right)$, we must have that $\theta \Phi\left(\frac{1+\theta}{u^{\prime}\left(c_{1}^{*}\right)}\right)<\theta \Phi\left(\frac{1+\theta}{u^{\prime}\left(c_{0}^{*}\right)}\right)$, for any $\theta$. However, (79) implies that $\tilde{\theta}_{1} \Phi\left(\frac{1+\tilde{\theta}_{1}}{u^{\prime}\left(c_{1}^{*}\right)}\right)>\tilde{\theta}_{0} \Phi\left(\frac{1+\tilde{\theta}_{0}}{u^{\prime}\left(c_{0}^{*}\right)}\right)$. Since $\theta \Phi\left(\frac{1+\theta}{u^{\prime}(c)}\right)$ is increasing in $\theta$, this implies that $\tilde{\theta}_{1}>\tilde{\theta}_{0}$. Thus, more firms are ex-post clean in the economy under $G_{1}$.

Lemma 5 (a) $y(\theta)<\theta q$, for all $\theta$, whenever $\phi>0$. (b) Suppose $\phi>0$. Then there is $\bar{\theta}(\phi)>0$ such that for all $\theta \leq \bar{\theta}(\phi)$, we have that $y(\theta)=0$. The quantity produced, $q(\theta, w)$, is decreasing in $\theta$ and in $w$. In addition, $\bar{\theta}^{\prime}(\phi)>0$.

Proof: (a) $y(\theta)<\theta q$, for all $\theta$, implies that $\lambda_{\theta}(\theta)=0$. Indeed, suppose there is a $\theta$ such that $\lambda_{\theta}(\theta)>0$ and $y(\theta)=\theta q$. Then $\lambda_{0}(\theta)=0$ and, since $h^{\prime}(0)=0,(16)$ gives

$$
-\phi-\phi \lambda_{\theta}(\theta)=0
$$

which is impossible when $\phi>0$.

(b) Consider the case of a firm with $y(\theta)=0$, for some $\theta$. In this case, $\lambda_{0}(\theta)>\lambda_{\theta}(\theta)=0$ and the firm's solution is

$$
\begin{aligned}
f^{\prime}(q)-\theta h^{\prime}(\theta q) & =w \\
h^{\prime}(\theta q) & \leq \phi
\end{aligned}
$$

The expression $f^{\prime}(q)-\theta h^{\prime}(\theta q)$ is strictly decreasing in $q$, so that (81) defines a function $q(\theta)$ that is uniquely defined for each $\theta$. It is easy to check that $q^{\prime}(\theta)<0$. In addition, $q(\theta)$ is decreasing in $w$, for all $\theta$ such that $y(\theta)=0$. Finally, notice that $h^{\prime}(\theta q)$ is increasing in $\theta$. Taking the total 
derivative, and using the expression for $q^{\prime}(\theta)$ from (81), we obtain ${ }^{17}$

$$
\frac{d h^{\prime}(\theta q)}{d \theta}=q\left(1-\frac{\theta^{2} h^{\prime \prime}}{\theta^{2} h^{\prime \prime}-f^{\prime \prime}}\right) h^{\prime \prime}>0
$$

where the inequality follows from the concavity of the production function. Thus, there is a $\bar{\theta}$ such that $y(\theta)=0$, for all $\theta<\bar{\theta}$. The threshold $\bar{\theta}$ is defined by

$$
h^{\prime}(\bar{\theta} q(\bar{\theta}))=\phi
$$

Whenever $\lambda_{\theta}(\theta)=0$, the emissions constraint is not binding, and, from $(81), q(\theta)$ is not an explicit function of $\phi$. Therefore, when $\phi$ increases, $\bar{\theta}$ must also increase by (83). Thus, more firms choose to reduce their emissions to a full extent when the price of permits increases.

Lemma 6 (a) Suppose $\phi>0$. Then, for all $\theta>\bar{\theta}(\phi)$, we have that $y(\theta, \phi)$ and $q(\theta, \phi, w)$ are such that $0<y<\theta q, \theta q-y$ is a constant function of $\phi$. (b) $w^{\prime}(\phi)<0$.

Proof: (a) Let us consider the case when $0<y(\theta)<\theta q$. Setting $\lambda_{\theta}(\theta)=\lambda_{0}(\theta)=0$, the solution of the firm's problem becomes,

$$
\begin{aligned}
f^{\prime}(q)-\theta h^{\prime}(\theta q-y) & =w \\
h^{\prime}(\theta q-y) & =\phi
\end{aligned}
$$

Replacing the expression for $h^{\prime}$ in the first equation, we obtain

$$
\begin{aligned}
f^{\prime}(q(\theta)) & =w+\theta \phi \\
h^{\prime}(\theta q(\theta)-y(\theta)) & =\phi
\end{aligned}
$$

For firms with $\theta>\bar{\theta}$, the solution is a pair $(q(\theta), y(\theta))$ that solves these equations. Notice that $q^{\prime}(\theta)<0$ whenever $\phi>0$. Also, $y^{\prime}(\theta)>0$, if $-f^{\prime \prime}(q) q / f^{\prime}(q) \geq 1$. Finally, if $\phi$ increases then $q(\theta)$ declines, in which case $y(\theta)$ is also decreasing in $\phi$.

(b) Given firms' optimal behavior, $w$ is given by

$$
w u^{\prime}\left(\int_{0}^{\bar{\theta}} f(q(\theta))-h(\theta q(\theta)) d G(\theta)+\int_{\bar{\theta}}^{\infty} f(q(\theta))-h(\theta q(\theta)-y(\theta)) d G(\theta)\right)=1
$$

\footnotetext{
${ }^{17}$ From (81), we have
}

$$
\left(f^{\prime \prime}-\theta^{2} h^{\prime \prime}\right) q^{\prime}(\theta)=\theta q h^{\prime \prime}
$$

Therefore,

$$
\frac{d h^{\prime}}{d \theta}=\theta h^{\prime \prime} q^{\prime}(\theta)+q h^{\prime \prime}=h^{\prime \prime}\left(\theta q^{\prime}(\theta)+q\right)=h^{\prime \prime}\left(\theta \frac{\theta q h^{\prime \prime}}{f^{\prime \prime}-\theta^{2} h^{\prime \prime}}+q\right)=q h^{\prime \prime}\left(1-\frac{\theta^{2} h^{\prime \prime}}{\theta^{2} h^{\prime \prime}-f^{\prime \prime}}\right) .
$$


Since $q(\theta)$ does not depend on $\phi$ when $\theta<\bar{\theta}$, we obtain

$$
u^{\prime} \frac{\partial w}{\partial \phi}+w u^{\prime \prime}\left(\int_{\bar{\theta}}^{\infty} w \frac{\partial q}{\partial \phi}+p \frac{\partial y}{\partial \phi} d G(\theta)\right)=0
$$

Since $\frac{\partial q}{\partial \phi}<0$ and $\frac{\partial y}{\partial \phi}<0$, we have $\frac{\partial w}{\partial \phi}<0$. When studying the general equilibrium effect of a rise in $\phi$, it is important to notice that the effect on $q(\theta)$ is somewhat tempered by the decline in $w$. Still, $q(\theta)$ and $y(\theta)$ remain decreasing as functions of $\phi$.

\section{An Extension: Futures Market}

In the emissions trading system studied in the body of the paper we assumed that the issuing authority assigns permits to firms at the start of a new remittance period. In this section, we show how our model can be extended to the case where the government sells permits rather than transferring them lump-sum and free of charge. ${ }^{18}$

Assume that firms receive signal $s=\theta+\varepsilon$ on the realization of their shock, $\theta$, at the start of the market. The random term $\varepsilon$ is drawn from a distribution $F$ and $E\left(\varepsilon_{i}\right)=0$, for all $i$. Given this structure, the firm's signal is also a firm's best guess for the true value of $\theta$. Once $s$ is observed, a firm can access a futures market to acquire or sell permits at a price $p$, for delivery at the remittance date. At this stage, the government sells an amount $T$ of permits (buys if $T<0$ ).

Then the true shock is realized and firms decide on their production and emission levels. At the remittance date, a spot market for permits opens, where firms can trade their permits at a price $\phi$. Finally, each firm presents an amount of permits equal to the amount of emissions, $y$.

We denote the value of entering the futures market with $m$ permits and shock $s$ by $V(m ; s)$ and the value of entering the spot market for permits with $m$ permits and shock value $s$ by $W(m ; \theta)$. Then, $V(m ; s)$ is defined by

$$
\begin{aligned}
V(m ; s) & =\max _{x} E_{\theta \mid s} W(m-x, x ; \theta) \\
\text { s.t. } x & \leq m
\end{aligned}
$$

while $W(m)$ solves

$$
\begin{aligned}
W(m, x ; \theta)= & \max _{x, q, y, m_{+}} f(q)-w q-h(\theta q-y)+\phi(m-y)+p x+\tau-\phi m_{+}+\beta E_{s} V\left(m_{+} ; s(92)\right. \\
& \text { s.t. } 0 \leq y \leq \theta q
\end{aligned}
$$

where $\tau$ is a lump-sum transfer. Using (92) to replace $W$ in (91), we obtain

$$
\begin{aligned}
V(m ; s)= & \max _{x \leq m} p x+\int_{\theta \mid s}\left[\max _{q, y} f(q)-w q-h(\theta q-y)+\phi(m-x-y)\right] \\
& +\max _{m_{+}} \beta E_{s} V\left(m_{+} ; s\right)-\phi m_{+} \\
& \text {s.t. } 0 \leq y \leq \theta q
\end{aligned}
$$

\footnotetext{
${ }^{18}$ More generally, we could investigate competing mechanisms for allocating permits in environments that include frictions, as in Eeckhout and Kircher (2010). This, however, is beyond the scope of the present paper.
} 
Given $M$, the market clearing conditions are

$$
\begin{aligned}
\int x(s) d H(s)+T & =0 \\
\int y(\theta, s) d H(s) d G(\theta)+m_{+} & =M+T \\
\int f(q(\theta))-h(\theta q(\theta)-y) d G(\theta) & =c
\end{aligned}
$$

The stock of permits follows the law of motion

$$
M_{+}=M-\int y(\theta) d G(\theta)+T
$$

Given a policy $\left\{T_{t}\right\}$, an equilibrium is a list of quantities and emissions $\left\{c_{t}, q_{t}(\theta), y_{t}(\theta)\right\}$, permittrading decisions $\left\{x_{t}(\theta), m_{t}(\theta)\right\}$, and prices $\left\{p_{t}, \phi_{t}\right\}$, such that, given prices, the list of decision variables solves the firms' and consumers' problems and markets clear. An equilibrium is stationary whenever the list of quantities and emissions is time independent; i.e., when $\left\{c_{t}, q_{t}(\theta), y_{t}(\theta)\right\}=$ $\{c, q(\theta), y(\theta)\}$, for all $t$.

We demonstrate that for any stationary policy $T$, there is a unique stationary equilibrium. We first solve the firm's problem. The first order conditions give

$$
\begin{aligned}
f^{\prime}(q)-\theta h^{\prime}(\theta q-y) & =w-\theta \phi \lambda_{\theta}(\theta) \\
h^{\prime}(\theta q-y)-\phi-\phi \lambda_{\theta}(\theta)+\phi \lambda_{0}(\theta) & =0 \\
p-\phi \lambda(s)-\phi & =0 \\
\beta E_{s} V_{m_{+}}\left(m_{+} ; s\right) & \leq \phi=\text { if } m^{\prime}>0
\end{aligned}
$$

where $\phi \lambda(s)$ is the Lagrange multiplier on the firm's constraint in the futures market, and $\phi \lambda_{\theta}(\theta)$, $\phi \lambda_{0}(\theta)$ are the multipliers on the constraints related to emissions reduction. Notice from (100) that all firms will exit the market holding the same amount of permits for the next period. The envelope condition gives

$$
V_{m}(m ; s)=\phi(1+\lambda(s))
$$

The workers' decision is still given by (4) and, using market clearing, we obtain an expression for the wage

$$
w u^{\prime}\left(\int f(q(\theta))-h(\theta q(\theta)-y(\theta)) d G(\theta)\right)=1
$$

From (99), it is clear that either $\lambda(s)>0$, for all $s$, and $p>\phi$, or $\lambda(s)=0$, for all $s$, and $p=\phi$. If $p>\phi$, then all firms sell their permits, so that $T=-M<0$. In addition, (95) implies that $\int y(\theta, s)+m_{+}=0$. Since $y(\theta, s) \geq 0$ and $m_{+} \geq 0$, this implies that $y(\theta, s)=0$, for all $s, \theta$. Clearly this is not efficient. The only candidate efficient equilibrium is one where $\lambda(s)=0$, for all $s$, so that $p=\phi$. This is equivalent to an equilibrium where the issuing authority would buy or sell permits in the spot market during the remittance period. Given $p=\phi$, the equilibrium is as in the text, and we can set $x(s)=-T$ and $y(\theta, s)=y\left(\theta, s^{\prime}\right)$, for all $\left(s, s^{\prime}\right)$, since firms are indifferent between holding permits across the two markets. 